Check for updates

Cite this: RSC Adv., 2017, 7, 46874

Received 6th July 2017

Accepted 29th September 2017

DOI: $10.1039 / c 7 r a 07454 a$

rsc.li/rsc-advances

\section{Effects of bromination of poly(3-hexylthiophene) on the performance of bulk heterojunction solar cells $\dagger$}

\author{
Senku Tanaka, (D) *a Siti Khadijah Binti Rosli, ${ }^{\text {a }}$ Ken Takada, ${ }^{\mathrm{b}}$ Norito Taniai, ${ }^{\text {b }}$ \\ Takuya Yoshitomi, ${ }^{a}$ Hideo Ando*c and Kouichi Matsumoto ${ }^{\text {b }}$
}

We examined the effects of delocalized $\pi$-electrons in poly(3-hexylthiophene) (P3HT) on the photovoltaic properties of a bulk heterojunction ( $\mathrm{BHJ}$ ) solar cell. The $\pi$-conjugated length of P3HT was controlled by modification of $\mathrm{P} 3 \mathrm{HT}$ through partial bromination at the 4-position of thiophene units. We investigated correlation between the degree of P3HT bromination $(2,11,22,37,66,84,100 \%)$ and the photovoltaic properties of $\mathrm{Br}$-P3HT:phenyl- $\mathrm{C}_{61}$-butyric acid methyl ester (PCBM) $\mathrm{BHJ}$ solar cells. The power conversion efficiency of the $11 \% \mathrm{Br}-\mathrm{P} 3 \mathrm{HT}$ :PCBM solar cell decreased to $56 \%$ of that of a pristine P3HT:PCBM solar cell. The main factor contributing to this decrease was lower short circuit currents. The photo absorption spectrum and the X-ray diffraction pattern of the $11 \% \mathrm{Br}$ - $\mathrm{P} 3 \mathrm{HT}$ film showed only slight differences to those of pristine $\mathrm{P} 3 \mathrm{HT}$, indicating the interchain $\pi$-stacking of the polymers was almost unaffected by the $11 \%$ bromination. These results suggest that an intrachain $\pi$-conjugation across more than 10 thiophene rings in the P3HT backbone is necessary to realize efficient charge transport in polymer domains. The 37\% Br-P3HT:PCBM cell showed only weak photovoltaic properties; both interand intrachain delocalization of $\pi$-electrons were disturbed by bromination.

\section{Introduction}

Organic solar cells ${ }^{\mathbf{1 - 3}}$ are promising candidate devices for clean and renewable energy sources. Among organic solar cell structures, bulk heterojunction (BHJ) devices based on a combination of poly(3-hexylthiophene) (P3HT) and phenyl- $\mathrm{C}_{61}$-butyric acid methyl ester (PCBM) are one of the most widely studied systems. ${ }^{4}$ Since the first report of the combination of P3HT and PCBM by Schilinsky et al., ${ }^{5}$ many experimental and theoretical studies have been reported., ${ }^{4,6,7}$ Although the limitations of the P3HT:PCBM devices have been elucidated theoretically, ${ }^{6}$ this system can still provide important insights for the further development of polymer photovoltaics.

One aspect of interest for the development of polymer solar cells is how the microscopic morphological and electronic structures of the polymers contribute to macroscopic device

${ }^{a}$ Department of Electric and Electronic Engineering, Faculty of Science and Engineering, Kindai University, Kowakae 3-4-1, Higashi-Osaka, Osaka 577-8502, Japan. E-mail: senku@ele.kindai.ac.jp; Tel: +81-6-6730-5880 ext. 4319

${ }^{b}$ Department of Chemistry, Faculty of Science and Engineering, Kindai University, Kowakae 3-4-1, Higashi-Osaka, Osaka 577-8502, Japan. E-mail: kmatsumo@chem. kindai.ac.jp; Tel: +81-6-6730-5880 ext. 4126

${ }^{c}$ Department of Physics, Faculty of Science, Yamagata University, Kojirakawa-Machi 14-12, Yamagata 990-8560, Japan. E-mail: ando@sci.kj.yamagata-u.ac.jp; Tel: +81-23628-4564

$\uparrow$ Electronic supplementary information (ESI) available. See DOI: 10.1039/c7ra07454a performance. The P3HT:PCBM system is suitable for investigation of these issues because of the well-established synthesis methods of $\mathrm{P}_{3} \mathrm{HT}^{8-10}$ and supporting research of its properties. $^{6,7}$ For example, both the regioregularity and molecular weight are closely related to the inter- and the intra-chain delocalization of $\pi$-electrons, which are important factors for charge transport in polymer films. ${ }^{7}$ Although many studies have demonstrated the importance of $\pi$-electron delocalization, few studies have attempted to control $\pi$-electron delocalization in a P3HT film to derive a quantitative relationship of how this factor affects device performance.

On this basis, we focused on quantitative understanding of the impact of $\pi$-conjugation length of polymer backbones on the photovoltaic properties of polymer solar cells. For this purpose, we needed to control the $\pi$-conjugation length of P3HT. One such modification method for P3HT, involving bromination, ${ }^{\mathbf{1 1}, \mathbf{1 2}}$ has been reported. It has been suggested that bromination of $\mathrm{P} 3 \mathrm{HT}$ disturbs the delocalization of $\pi$-conjugated electrons on the P3HT backbone. ${ }^{\mathbf{1 2 - 1 4}}$ In this study, we examined the effects of inter- and intra-chain delocalization of $\pi$-electrons in a P3HT on the device performances, using P3HT brominated to varying degrees. The relationship between the degree of delocalization of $\pi$-electrons along the P3HT backbone and the photovoltaic properties of the resulting Br-P3HT:PCBM BHJ solar cells is discussed semiquantitatively. Density functional theory (DFT) calculations support conjugation control by bromination, associated with 
marked torsion of inter-ring $\mathrm{S}-\mathrm{C}-\mathrm{C}-\mathrm{S}$ dihedral angles in the P3HT backbone.

\section{Experimental}

\section{Synthesis of pristine P3HT, fully and partially brominated P3HTs}

All materials for the synthesis of $\mathrm{P} 3 \mathrm{HT}$ and fully and partially $\mathrm{Br}$ P3HTs were obtained from commercial suppliers and used without further purification. All reactions were performed under a nitrogen atmosphere. ${ }^{1} \mathrm{H}$ and ${ }^{13} \mathrm{C}$ NMR spectra were recorded in $\mathrm{CDCl}_{3}$ on a Varian Mercury $300\left({ }^{1} \mathrm{H}, 300 \mathrm{MHz} ;{ }^{13} \mathrm{C}\right.$, $75 \mathrm{MHz})$ and a JEOL JNM-ECS $400\left({ }^{1} \mathrm{H}, 400 \mathrm{MHz} ;{ }^{13} \mathrm{C}, 100 \mathrm{MHz}\right)$ spectrometer with $\mathrm{Me}_{4} \mathrm{Si}$ as an internal standard unless otherwise noted. Thin-layer chromatography was performed on Merck pre-coated silica gel F254 plates (thickness $0.25 \mathrm{~mm}$ ). Flash chromatography was performed on a silica gel column (Kanto Chem. Co., Silica Gel N, spherical, neutral, 40-100 $\mu \mathrm{m}$ ). Gel permeation chromatography (GPC) analysis was performed at $40{ }^{\circ} \mathrm{C}$ by using HITACHI L- $4000 \mathrm{H}$ UV detector, HITACHI L6300 Intelligent Pump, and SHIMAZU COLUMN OVEN CTO10A, in which KF-803L (Shodex), KF-805L (Shodex), and KF-G 4A (Shodex, guard column) were used as GPC column. Tetrahydrofuran was used in the GPC analysis at $1.0 \mathrm{~mL} \mathrm{~min}^{-1}$. A polystyrene standard (Shodex Standard, SM-105 and SL-105) was used to estimate the molecular weight.

3-Hexylthiophene ${ }^{\mathbf{1 5}}$ and 2,5-dibromo-3-hexylthiophene ${ }^{\mathbf{1 6}}$ were prepared according to literature procedures. P3HT was synthesized twice according to a literature procedure, ${ }^{9}$ and two P3HT samples were coupled for use in subsequent bromination reactions of $\mathrm{P} 3 \mathrm{HT}$ as same lot. The regioregular head-to-tail ratio of $\mathrm{P} 3 \mathrm{HT}$ thus synthesized was determined to be approximately $96 \%$ as estimated from ${ }^{1} \mathrm{H}$ NMR analysis, in which the number-average molecular weight and polydispersity of synthesized P3HT derived from the GPC diagrams were $M_{\mathrm{n}}=$ $49200, M_{\mathrm{w}} / M_{\mathrm{n}}=1.72$. Thus, brominated P3HT was synthesized using same sample of P3HT.

Fully or partially brominated P3HT (Fig. 1(a)) was synthesized according to a literature procedure, ${ }^{14}$ in which partially brominated P3HT was prepared by changing the ratio of $\mathrm{N}$-bromosuccinimide (NBS) toward P3HT (the ratio of NBS toward P3HT was $1 \%\left(M_{\mathrm{n}}=28500, M_{\mathrm{w}} / M_{\mathrm{n}}=1.74\right), 10 \%\left(M_{\mathrm{n}}=48800\right.$,

(a)

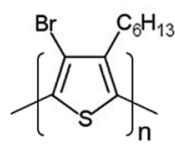

(b)
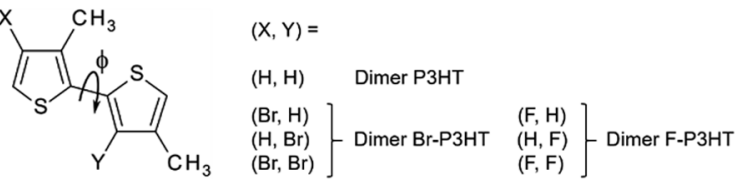

Fig. 1 (a) Molecular structure of $\mathrm{Br}$-P3HT. (b) Theoretical dimer (X, Y) models of P3HT, Br-P3HT, and F-P3HT and the torsion of the interring $\mathrm{S}-\mathrm{C}-\mathrm{C}-\mathrm{S}$ dihedral angle $\phi$.
$\left.M_{\mathrm{w}} / M_{\mathrm{n}}=1.83\right), 15 \%\left(M_{\mathrm{n}}=51200, M_{\mathrm{w}} / M_{\mathrm{n}}=1.74\right), 30 \%\left(M_{\mathrm{n}}=\right.$ $\left.59000, M_{\mathrm{w}} / M_{\mathrm{n}}=1.95\right), 50 \%\left(M_{\mathrm{n}}=49000, M_{\mathrm{w}} / M_{\mathrm{n}}=1.98\right), 70 \%$ $\left(M_{\mathrm{n}}=49500, M_{\mathrm{w}} / M_{\mathrm{n}}=1.90\right)$, and $100 \%\left(M_{\mathrm{n}}=50600, M_{\mathrm{w}} / M_{\mathrm{n}}=\right.$ 1.67)). The degree of $\mathrm{Br}$ introduced into the P3HT backbone of each sample was evaluated by X-ray photoelectron spectroscopy. The $\mathrm{Br}$ concentrations measured for each sample were $2 \%, 11 \%$, $22 \%, 37 \%, 66 \%, 84 \%$, and $100 \%$. Hereafter, we refer to the $\mathrm{Br}$ concentration as the bromination degree. GPC curves and NMR spectra of each sample were shown in ESI. $\dagger$

\section{Characterization of single polymer layers}

To evaluate the synthesized Br-P3HT characteristics, single layer Br-P3HT films were deposited on glass substrates. Each BrP3HT solution (10 $\mathrm{mg} \mathrm{mL}^{-1}$ ) was prepared in 1,2-dichlorobenzene as a solvent. The solutions were deposited on pre-cleaned glass substrates by spin coating (700 rpm, $1 \mathrm{~min}$ ). The samples were then annealed at $120^{\circ} \mathrm{C}$ for $5 \mathrm{~min}$ in the glove box. UV-vis absorption spectra were measured from single layers of the samples with a Shimadzu UV-1850 spectrometer. X-ray diffraction (XRD) measurements were used for structural analysis of the films. XRD patterns were measured on a Rigaku SmartLab with $\mathrm{Cu} \mathrm{K} \alpha$ radiation.

\section{Device fabrication}

$\mathrm{BHJ}$ solar cells of Br-P3HT and PCBM were fabricated as follows. Pre-patterned indium tin oxide (ITO)-coated glass substrates were cleaned by sequential sonication in 2-propanol, acetone, and 2-propanol. The films were then subjected to a $\mathrm{UV} / \mathrm{O}_{3}$ treatment for $5 \mathrm{~min}$. These procedures were performed under ambient conditions in air. For the electron transport layer, a thin film of $\mathrm{ZnO}$ was deposited on the ITO by a sol-gel method. Zinc acetate dihydrate $\left[\mathrm{Zn}\left(\mathrm{CH}_{3} \mathrm{COO}\right)_{2} \cdot 2 \mathrm{H}_{2} \mathrm{O}\right](0.75 \mathrm{M})$ with ethanolamine $(0.75 \mathrm{M})$ in 2-methoxyethanol was used as the ZnO sol-gel precursor. The sol-gel precursor was spincoated on the ITO substrate at $1000 \mathrm{rpm}$ for $1 \mathrm{~min}$. Next, the samples were annealed on a hot plate at $300{ }^{\circ} \mathrm{C}$ for $10 \mathrm{~min}$ in a $\mathrm{N}_{2}$ purged glove box. After the annealing process, the samples were rinsed with deionized water and then dried on a hot plate at $120{ }^{\circ} \mathrm{C}$ for $5 \mathrm{~min}$. The Br-P3HT (bromination degree: $2 \%$, $11 \%, 22 \%, 37 \%, 66 \%, 84 \%$, and $100 \%)$ and PCBM (>99.5\%, Sigma Aldrich) were dissolved in 1,2-dichlorobenzene with $1.5 \mathrm{wt} \%$ (P3HT : PCBM = $1: 1$ by weight) and then stirred at $60{ }^{\circ} \mathrm{C}$ for $8 \mathrm{~h}$ in a glove box. For comparison, a pristine P3HT (unbrominated) and PCBM solution was also prepared. After stirring, the solutions were passed through a $0.45 \mu \mathrm{m}$ polytetrafluoroethylene syringe filter. Then the solutions were deposited on the ZnO layer by spin coating at $600 \mathrm{rpm}$ for $1 \mathrm{~min}$ in an ambient atmosphere. ${ }^{17}$ The samples were moved into a glove box and allowed to dry over $2 \mathrm{~h}$. For the top electrode, a sheet of freestanding carbon nanotube (CNT)-sheet ${ }^{18}$ was placed onto the P3HT:PCBM layer. The CNT-sheet was drawn laterally from the side of a chemical vapor deposition grown oriented multiwalled CNT forest (Lintec of America, NSTC). A dispersed solution of Ag nanorods (Activegrid G-J.5, C3Nano) was then dropped onto the CNT-sheet. The samples were annealed at $120{ }^{\circ} \mathrm{C}$ for $5 \mathrm{~min}$ in the glove box. Finally, a solution 
of poly (3,4-ethylenedioxythiophene)-poly (styrenesulfonate) (PEDOT:PSS) (1.3 wt\% dispersed in $\mathrm{H}_{2} \mathrm{O}$, conductive grade, Aldrich), mixed with methanol in a $1: 3$ mass ratio, was spin coated $(3000 \mathrm{rpm}, 40 \mathrm{~s})$ on top of the CNT-sheet:Ag nanorod layer. The device was then annealed at $120{ }^{\circ} \mathrm{C}$ for $5 \mathrm{~min}$ in the glove box. The overall structure of the OPV devices used in the present study was the glass/ITO/ZnO/P3HT:PCBM/CNTsheet:Ag nanorod:PEDOT:PSS (from bottom to top). The completed devices contained four cells with an active area of 0.06-0.08 $\mathrm{cm}^{2}$ each. We fabricated 8 to 12 cells for each condition.

\section{Current density-voltage measurements}

The current density-voltage $(J-V)$ characteristics of the solar cells were measured in ambient atmosphere using an Agilent B2911A source measurement unit. For the photo $J-V$ characteristics, a solar simulator (HAL-320, Asahi Spectra) was used as a light source and calibrated to $100 \mathrm{~mW} \mathrm{~cm} \mathrm{~cm}^{-2}$, AM1.5 solar spectrum. A shadow mask was used to define the area of illumination.

\section{Quantum chemical model and calculation}

To theoretically provide some microscopic information about how bromination influences on the conjugation, we employed dimer (X, Y) models of the pristine P3HT and Br-P3HT. As shown in Fig. 1(b), the (X, Y) denotes two substituent groups in the adjacent thiophene rings. The hexyl groups were modeled as methyl groups, and both ends of the P3HT chain were terminated by hydrogen. We calculated the torsional potential energy curves (PECs) along the inter-ring $\mathrm{S}-\mathrm{C}-\mathrm{C}-\mathrm{S}$ dihedral angle $\phi$ to investigate geometrical flexibility of the chain. When constructing the PECs, all geometrical parameters except for the dihedral angle were fully optimized with the DFT(B3LYP) method $^{19-21}$ and the cc-pVDZ basis set. ${ }^{22-24}$ Analogous dimer models for fluorination of the P3HT were also investigated for comparison. The self-consistent-field stability analysis ${ }^{25,26}$ confirmed that the singlet electronic states obtained were the stable electronic configurations. All quantum chemical calculations were carried out with Gaussian $09 .^{27}$

\section{Results}

\section{Optical and structural properties}

To investigate the optical properties of the synthesized $\mathrm{Br}$ P3HT, we measured the UV-vis absorption spectrum of singlelayer films (Fig. 2). The absorption spectrum showed gradual changes with increasing bromination degree, including a shift of the absorption edge to shorter wavelengths and a decrease of the absorption in the visible region. Note that the absorption spectra of the $2 \%$ bromination film showed similar shape compared with the spectrum of pristine P3HT. The absorption spectra of $11 \%$ and $22 \%$ bromination films showed a slight shift toward shorter wavelengths but still showed similar shape with that of pristine $\mathrm{P} 3 \mathrm{HT}$. The absorption spectra of the films having larger than $37 \%$ bromination showed significant change in the spectral shape. These results were qualitatively consistent

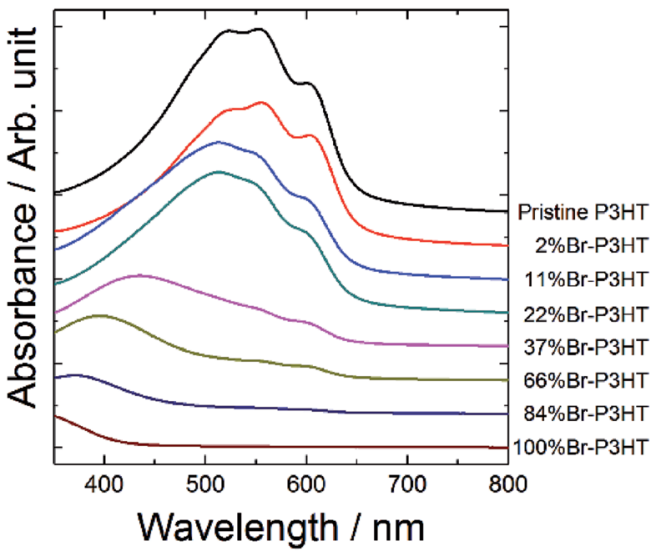

Fig. 2 Absorption spectra of Br-P3HT film. Absorption spectrum of a pristine P3HT (unbrominated) film is also shown for comparison. Spectra are offset for clarity.

with those of a previous report. ${ }^{12}$ During the preparation process of the thin films, it was found that the viscosity of the solution was also affected by bromination, although the quantitative measurement was not performed. The viscosity of the solution was decreased with increasing the bromination degree. Thus the low absorbance in the high bromination degree $(>37 \%)$ samples could be caused by the low viscosity. The effect of the difference in viscosity on the film thickness of the solar cells is discussed later.

Next, we investigated the crystallinity of the polymer films. Fig. 3 shows the XRD patterns of the Br-P3HT films. An XRD pattern of pristine P3HT is also shown for comparison. The pristine $\mathrm{P} 3 \mathrm{HT}$ film showed a diffraction peak at $5.4^{\circ}$ corresponding to a lamellae structure..$^{12,28,29}$ The peak was observed on the $2-37 \%$ Br-P3HT films, whereas its intensity was clearly lower in the $37 \%$ Br-P3HT film. The crystallinity of the film got slightly decreased with increasing the bromination degree. In the XRD pattern of $37 \%$ Br-P3HT film, a small diffraction peak

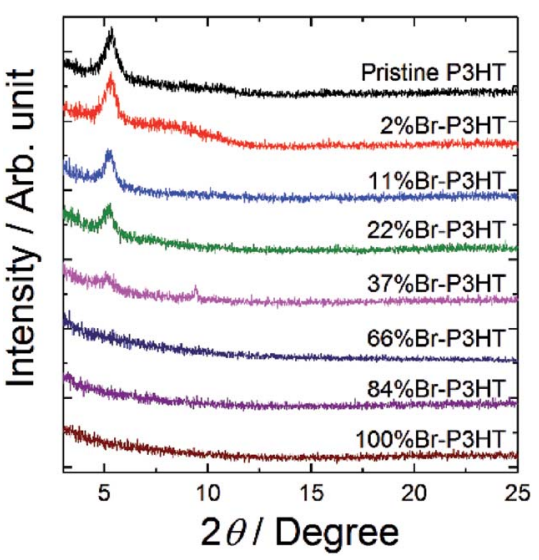

Fig. $3 X$-ray diffraction pattern of pristine and brominated P3HT films. Curves are offset for clarity. The peak at around $2 \theta=5.4^{\circ}$ corresponds to diffraction from the lamellar structure of alkyl side chain direction. The height of the peak is proportional to the crystallinity of the samples. 
was observed at $9.5^{\circ}$. The origin of the peak has not yet been identified. The average crystal domain size for each film was calculated using the Scherrer equation (see ESI p. S1 $\dagger$ ). The domain size of pristine P3HT was approximately $11 \mathrm{~nm}$, whereas the 2-22\% Br-P3HTs showed slightly larger size of 13$14 \mathrm{~nm}$. No diffraction peak was observed in films having bromination degree greater than $66 \%$.

\section{Photovoltaic properties}

The photovoltaic properties were examined for Br-P3HT:PCBM BHJ cells made from the synthesized Br-P3HTs. Fig. 4 shows the bromination degree dependence of the short-circuit current density $\left(J_{\mathrm{SC}}\right)$, open circuit voltage $\left(V_{\mathrm{OC}}\right)$, fill factor $(\mathrm{FF})$, and power conversion efficiency $(\eta)$ estimated from the $J-V$ characteristics. It was confirmed that the photovoltaic properties of each cell showed no significant degradation during the experimental period. The relatively low $\eta$ compared with previously reported values of $\mathrm{P} 3 \mathrm{HT}$ :PCBM $\mathrm{BHJ}$ systems may be attributed to the semi-transparent CNT-sheet employed as the top electrode $^{30}$ Note, however, that a solar cell with the same BHJ structure but a different top structure (PEDOT:PSS/Au) showed similar $\eta$, indicating that the CNT-sheet electrode does not have a marked effect on the photocurrent generation processes (see ESI p. S2 $\dagger$ ). The solar cells featuring P3HT with a higher bromination degree exhibited lower $\eta$. The solar cells made with a bromination degree greater than $66 \%$ showed almost no photovoltaic effect $(\eta<0.01 \%)$ and a short circuit was often observed. The short circuit in the high bromination degree cells was partly due to a decrease in film thickness, which was caused by the low viscosity of solution as mentioned above. We note, (a)

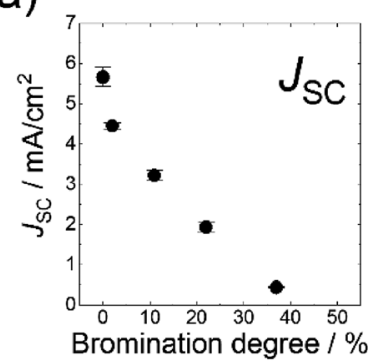

(c)

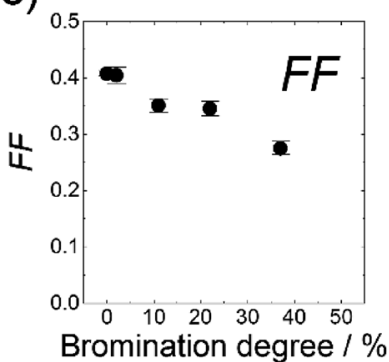

(b)

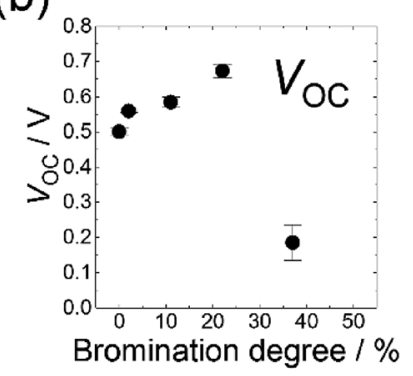

(d)

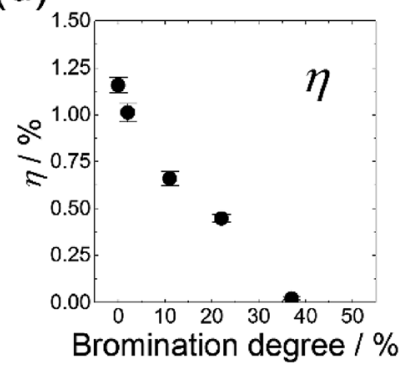

Fig. 4 Bromination degree dependence of the photovoltaic properties of P3HT:PCBM bulk heterojunction solar cells; (a) short circuit current density, (b) open circuit voltage, (c) fill factor, and (d) power conversion efficiency. The error bars indicate standard error. however, that the thickness of the $\mathrm{BHJ}$ layer in $2-37 \% \mathrm{Br}-\mathrm{P} 3 \mathrm{HT}$ cells was similar to that in the pristine P3HT cell within the measurement errors (see ESI p. S1 $\dagger$ ).

The average $\eta$ of $2 \%$ Br-P3HT (1.01\%) showed a slight decrease compared with that of pristine P3HT (1.16\%). The average $\eta$ notably decreased to $0.66 \%$ for $11 \% \mathrm{Br}-\mathrm{P} 3 \mathrm{HT}$, and to $0.01 \%$ for the $37 \% \mathrm{Br}-\mathrm{P} 3 \mathrm{HT}$. The decrease of $\eta$ was mainly caused by the low $J_{\mathrm{SC}}$ values. The $J_{\mathrm{SC}}$ decreased almost exponentially as the bromination degree increased to $37 \%$. The FF also decreased with increasing bromination degree. On contrary, the $V_{\mathrm{OC}}$ showed a slight increase as the bromination degree was increased to $22 \%$. In the case of $37 \% \mathrm{Br}-\mathrm{P} 3 \mathrm{HT}$ the $V_{\text {OC }}$ dropped to $0.19 \mathrm{~V}$. These results suggested that the bromination of P3HT affected multiple photovoltaic processes in the P3HT:PCBM BHJ cells. Similar bromination effects on the photovoltaic properties were observed in the solar cells which were fabricated by another synthesized batch of brominated P3HTs (relatively low regioregularity (83\%) and different $M_{\mathrm{n}}$ and $M_{\mathrm{w}} / M_{\mathrm{n}}$, see ESI p. S3†).

\section{Potential energy curve (PEC) of inter-ring S-C-C-S dihedral torsion}

The torsional PECs of the dimer models for P3HT and Br-P3HT are shown in Fig. 5(a). The overall energy profile of the dimer $(\mathrm{H}$,
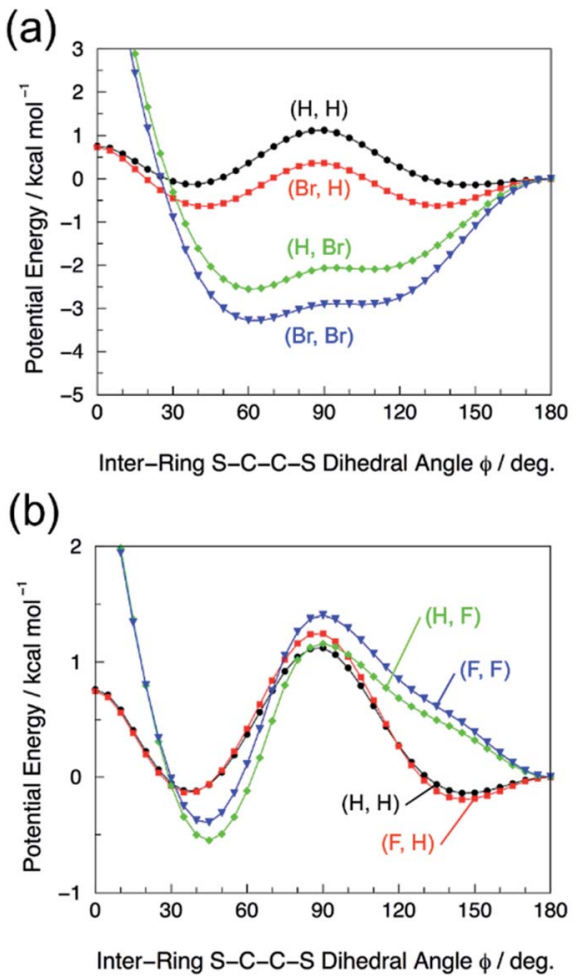

Fig. 5 (a) Torsional energy curves of the dimer P3HT and $\mathrm{Br}-\mathrm{P} 3 \mathrm{HT}$ models, and (b) torsional energy curves of the dimer P3HT and F-P3HT models. The optimized conformations at $\phi=180^{\circ}$, whose structural formula are shown in Fig. 1(b), belong to the $C_{S}$ point group and the energies are used as the reference energy (zero). The potential energy curves were constructed with the DFT(B3LYP)/cc-pVDZ optimization at $\Delta \phi=5^{\circ}$ intervals from $0^{\circ}$ to $180^{\circ}$. 
H) model was in reasonable agreement with other theoretical results. ${ }^{31-33}$ The PEC had a double-well shape and the two minima of $-0.1 \mathrm{kcal} \mathrm{mol}^{-1}$ were found in proximity to the coplanar conformations $\left(\phi=38^{\circ}\right.$ and $\left.147^{\circ}\right)$. There was a small maximum of $1.1 \mathrm{kcal} \mathrm{mol}^{-1}$ at $\phi=88^{\circ}$, where the individual thiophene rings are almost orthogonal. The PEC of the dimer $(\mathrm{Br}, \mathrm{H})$ model and also the PECs of all dimer models for F-P3HT (Fig. 5(b)) resembled that of the dimer $(\mathrm{H}, \mathrm{H})$ model. In contrast, the PECs of the dimer $(\mathrm{H}, \mathrm{Br})$ and $(\mathrm{Br}, \mathrm{Br})$ models had a profile significantly different from that of the dimer $(\mathrm{H}, \mathrm{H})$ model. The energy minima were located far from the coplanar conformation, or closer to the orthogonal conformation, and the PECs around the minima were almost flat. In the dimer $(\mathrm{H}, \mathrm{Br})$ model, for example, the minimum of $-2.6 \mathrm{kcal} \mathrm{mol}^{-1}$ was located at $\phi$ $=61^{\circ}$ and a small shoulder was found around $\phi=90^{\circ}$.

\section{Discussion}

Here, we discuss the mechanism underlying the decrease of $\eta$ through bromination of P3HT. Photocurrent generation process consists of four consecutive steps: ${ }^{2}$ exciton generation by photo absorption, exciton diffusion, dissociation into free charge pairs (charge separation), and charge transport. First, we consider the effect of bromination of P3HT on exciton generation efficiency. As previously reported, the bromination of P3HT increases the bandgap of the polymer. ${ }^{11,14}$ Indeed, the absorption edge was blue shifted as the bromination degree was increased (Fig. 2), suggesting an increase of the bandgap through bromination. The wider bandgap in this energy region leads to a lower number of absorbed photons owing to poorer overlap of the absorbance with the solar spectrum. Thus, we expected $J_{\mathrm{SC}}$ to decrease as the bromination degree was increased. The decrease in exciton generation was one factor contributing to the decrease in $\eta$ in brominated P3HT. However, the $J_{\mathrm{SC}}$ decreased by nearly $43 \%$ despite only a small change in the absorption spectrum of the thin films of the 11\% Br-P3HT and pristine $\mathrm{P} 3 \mathrm{HT}$. In addition, the incident photon to current conversion efficiency of 11\% Br-P3HT cell showed significant decrease compared to the change in the absorption spectrum (see ESI p. S5 $\dagger$ ). Thus, the observed $J_{\text {SC }}$ decrease cannot be explained solely by decreased exciton generation efficiency; the effects of bromination on the other three steps should also be considered.

Next, we discuss the effects of P3HT bromination on charge transport process. For bromination degrees $<11 \%$, it is presumed that bromination of P3HT had no effect on the efficiency of the exciton diffusion and charge separation. The validity of this assumption is discussed later. For charge transport in a P3HT domain, both conjugation of the backbone (intrachain delocalization of $\pi$-electrons) and cofacial $\pi-\pi$ stacking of the conjugated backbones (interchain delocalization of $\pi$-electrons) are important. It has been reported both experimentally ${ }^{\mathbf{1 1 , 1 4}}$ and theoretically ${ }^{\mathbf{1 3 , 3 4}}$ that bromine substitution of thiophene rings disturbs delocalization of $\pi$-electrons along the polymer backbone. Our theoretical calculations of dimer P3HT models (Fig. 1(b)) suggest that the bromination at the Y-position of the dimer $\mathrm{P} 3 \mathrm{HT}$ results in notable inter-ring
S-C-C-S dihedral torsion of $\phi \sim 60^{\circ}$ (Fig. 5(a)), where the $\pi$ conjugation is relatively decoupled. The fluorination, by contrast, did not significantly change the torsional potential energy curve of the dimer P3HT model (Fig. 5(b)), regardless of the different electronic substituent effects (i.e. inductive withdrawing and resonance donation) of the fluoro group. Molecular origins of the inter-ring $\mathrm{S}-\mathrm{C}-\mathrm{C}-\mathrm{S}$ dihedral torsion and their influence on the $\pi$ conjugation and the excitation energy are presented in our theoretical paper. ${ }^{35}$

The blue-shift in the absorption spectrum also suggests that the intrachain delocalization of $\pi$-electrons on the backbone was disturbed by bromination. Moreover, the present results provide a semi-quantitative understanding of the effects of intrachain delocalization of $\pi$-electrons on charge transport. The 11\% Br-P3HT featured approximately one brominated thiophene ring per nine polythiophene backbone on average; thus, the intrachain delocalization of $\pi$-electrons on the backbone was limited compared with that of pristine P3HT. The similarities between the XRD pattern of $11 \% \mathrm{Br}-\mathrm{P} 3 \mathrm{HT}$ and that of pristine $\mathrm{P} 3 \mathrm{HT}$ suggested that interchain packing was not strongly affected by $11 \%$ bromination. Thus, the decrease in the $\eta$ at $11 \%$ Br-P3HT may be attributed to limited charge transport over approximately nine delocalized thiophene rings. The decrease of $J_{\mathrm{SC}}$ at $2 \% \mathrm{Br}-\mathrm{P} 3 \mathrm{HT}$ may indicate that $\pi$-electrons delocalized across $\sim 50$ thiophene rings did not give the inherent charge transport characteristics of P3HT. The detailed analysis in the range of low bromination degree is now in progress.

In addition to the effect of intrachain delocalization of $\pi$ electrons, bromine substitution on the thiophene ring may act as charge trapping and exciton quenching sites. Indeed, Kim et $a l .^{36}$ have reported that bromine end groups of P3HT can introduce hole traps, although the effect is relatively modest. In the present study, the charge-trapping effect and the excitonquenching effects of bromine were related to decreasing solar cell performance. However, it should be noted that the largest $V_{\text {OC }}$ was observed for the $22 \%$ Br-P3HT:PCBM solar cell. The $V_{\text {OC }}$ of a conjugated polymer-PCBM solar cell is linearly related to the energy difference between the highest occupied molecular orbital (HOMO) of the polymer and the lowest unoccupied molecular orbital of PCBM. ${ }^{37}$ As mentioned above, the bandgap of the P3HT was increased by bromination. Thus, the increase of $V_{\mathrm{OC}}$ with bromination indicates that the charge carriers were transported through HOMO states of the Br-P3HT. Thus, we presume that the charge trapping and exciton quenching effects of bromine substitution were limited. Such effects may be considered relatively modest in line with the previous report. ${ }^{36}$

Another aspect that has considerable influence on device performance is the interchain delocalization of $\pi$-electrons. It is known that a thin film of the regioregular P3HT forms a lamellar structure with $\pi-\pi$ stacking of polythiophene chains and stacking of alkyl side chains. ${ }^{38,39}$ In the case of Br-P3HT, the large ionic radius of bromine substituted onto the thiophene ring could lead to steric interactions with adjacent polymer molecules. As shown in Fig. 3, the XRD patterns demonstrated that the crystallinity of the polymer film decreased with increasing bromination degree. The low crystallinity suggested 
poor interchain $\pi-\pi$ stacking in the thin films. Indeed, it has been reported that the photo luminescence yield of Br-P3HT films is higher than that of P3HT films, and the enhancement is attributed to suppression of $\pi-\pi$ stacking. ${ }^{36}$ The weakened $\pi-$ $\pi$ stacking suppresses interchain delocalization of $\pi$-electrons between the polymer chains. For charge transfer in the P3HT films, the delocalization of electronic states in the $\pi-\pi$ stacking direction is important. It has been pointed out that charge carriers and excitons delocalized over several neighboring chains $^{\mathbf{4 0}}$ contribute to high performance in efficient organic electronic devices, such as field effect transistors, ${ }^{38,41}$ and solar cells. ${ }^{10,29,42}$ Thus, the weak photovoltaic effect in the BHJ cells with a bromination degree higher than $37 \%$ was likely related to poor interchain delocalization of $\pi$-electrons, in addition to the effects of poor intrachain delocalization and the thin film due to the low viscosity.

Finally, we note an issue for further consideration. Unfortunately it is difficult to quantitatively distinguish the contributions of bromination to exciton diffusion, charge separation, and the charge transport, from the present results. Both the exciton diffusion length and charge separation efficiency were reduced in the $\mathrm{Br}-\mathrm{P} 3 \mathrm{HT}$ with high bromination degrees; these properties are strongly related to the electronic overlap with neighboring polymer chains and PCBM molecules. However, in the low bromination degree range $(<11 \%)$, bromination likely had less effect on exciton diffusion and charge separation. As shown in Fig. 2 and 3, the differences in the absorption spectra and XRD patterns of these polymer from those of pristine $\mathrm{P} 3 \mathrm{HT}$ were relatively small. Thus it is reasonable to consider that $\sim 11 \%$ Br-P3HT had similar properties to pristine P3HT in terms of its exciton diffusion length and the charge separation efficiency. At a bromination degree greater than $\sim 37 \%$ the absorption spectrum and the XRD patterns began to show a change in shape, which may indicate the onset of the negative effects of bromination. Further detailed measurements of the correlation between the bromination degree up to about $30 \%$ and the device performance are required to understand this issue.

\section{Conclusions}

We examined the effect of bromination of P3HT on the photovoltaic properties of P3HT:PCBM BHJ solar cells. The bromination of $\mathrm{P} 3 \mathrm{HT}$ decreased the $J_{\mathrm{SC}}$ and the $\mathrm{FF}$ of solar cells compared with the performance of a pristine P3HT:PCBM solar cell. The $\eta$ decreased with increasing bromination degree and the photovoltaic properties were almost lost for the $37 \% \mathrm{Br}$ P3HT:PCBM cell. The decrease in the photovoltaic properties can be partially attributed to the decreased absorption in the visible range by the bromination. Another reason is the reduced delocalization of $\pi$-electrons across both intra- and inter-chain channels. A decrease of $J_{\mathrm{SC}}$ in the 11\% Br-P3HT:PCBM cell suggested that a $\pi$-conjugation length of nine thiophene rings was insufficient for achieving efficient charge transport in the polymer domains. A decrease of crystallinity in the polymer films was observed for a bromination degree of larger than $37 \%$; the suppression of delocalization of $\pi$-electrons between neighboring chains likely also contributed to the loss of photovoltaic properties for films with high bromination degrees. This study suggests that the control of both of the intrachain and the interchain delocalization of $\pi$-electrons is required for the ideal electron transport in organic solar cells.

\section{Conflicts of interest}

There are no conflicts of interest to declare.

\section{Acknowledgements}

A part of this study was supported by JSPS KAKENHI Grant Number 26390048 and MEXT-Supported Program for the Strategic Research Foundation at Private Universities S1411036. The authors would like to thank the Nano-Science \& Technology Center, LINTEC OF AMERICA, Inc. for providing the carbon nanotube forests. The authors appreciate Prof. Yusaku Suenaga and Prof. Manabu Ishifune at Kindai University for GPC analysis.

\section{Notes and references}

1 H. Spanggaard and F. C. Krebs, Sol. Energy Mater. Sol. Cells, 2004, 83, 125.

2 H. Hoppe and N. S. Sariciftci, J. Mater. Res., 2004, 19, 1924.

3 K. A. Mazzio and C. K. Luscombe, Chem. Soc. Rev., 2015, 44, 78.

4 M. T. Dang, L. Hirsch and G. Wantz, Adv. Mater., 2011, 23, 3597.

5 P. Schilinsky, C. Waldauf and C. J. Brabec, Appl. Phys. Lett., 2002, 81, 3885.

6 G. Dennler, M. C. Scharber and C. J. Brabec, Adv. Mater., 2009, 21, 1323.

7 F. Laquai, D. Andrienko, R. Mauer and P. W. M. Blom, Macromol. Rapid Commun., 2015, 36, 1001.

8 R. D. McCullough, Adv. Mater., 1998, 10, 93.

9 R. S. Loewe, P. C. Ewbank, J. Liu, L. Zhai and R. D. McCullough, Macromolecules, 2001, 34, 4324.

10 P. Kohn, S. Huettner, H. Komber, V. Senkovskyy, R. Tkachov, A. Kiriy, R. H. Friend, U. Steiner, W. T. S. Huck, J.-U. Sommer and M. Sommer, J. Am. Chem. Soc., 2012, 134, 4790.

11 Y. Li, G. Vamvounis, J. Yu and S. Holdcroft, Macromolecules, 2001, 34, 3130.

12 Y. Li, G. Vamvounis and S. Holdcroft, Macromolecules, 2002, 35, 6900 .

13 E. F. De Oliveira, A. Camilo-Jr, L. C. Da Silva-Filho and F. C. Lavarda, J. Polym. Sci., Part B: Polym. Phys., 2013, 51, 842.

14 B. Koo, E. M. Sletten and T. M. Swager, Macromolecules, 2015, 48, 229.

15 F. Banishoeib, A. Henckens, S. Fourier, G. Vanhooyland, M. Breselge, J. Manca, T. J. Cleij, L. Lutsen, D. Vanderzande, L. H. Nguyen, H. Neugebauer and N. S. Sariciftci, Thin Solid Films, 2008, 516, 3978.

16 B. Pal, W. Yen, J. Yang and W. Su, Macromolecules, 2007, 40, 8189. 
17 This preparation condition of $\mathrm{BHJ}$ layer led slightly thicker thickness of the BHJ layer compared with the optimized thickness (ca. $100 \mathrm{~nm}$. For example, see W. Ma et al., Adv. Funct. Mater., 2005, 15, 1617.) for a conventional device. However, in the case of using a semi-transparent CNTsheet electrode, we found that the present condition (slightly thicker than the usual $\mathrm{BHJ}$ layer) showed better efficiency.

18 M. Zhang, S. Fang, A. A. Zakhidov, S. B. Lee, A. E. Alie, C. D. Williams, K. R. Atkinson and R. H. Baughman, Science, 2005, 309, 1215.

19 A. D. Becke, J. Chem. Phys., 1993, 98, 5648.

20 C. Lee, W. Yang and R. G. Parr, Phys. Rev. B: Condens. Matter Mater. Phys., 1988, 37, 785.

21 B. Miehlich, A. Savin, H. Stoll and H. Preuss, Chem. Phys. Lett., 1989, 157, 200.

22 T. H. Dunning Jr, J. Chem. Phys., 1989, 90, 1007.

23 D. E. Woon and T. H. Dunning Jr, J. Chem. Phys., 1993, 98, 1358.

24 A. K. Wilson, D. E. Woon, K. A. Peterson and T. H. Dunning Jr, J. Chem. Phys., 1999, 110, 7667.

25 R. Seeger and J. A. Pople, J. Chem. Phys., 1977, 66, 3045.

26 R. Bauernschmitt and R. Ahlrichs, J. Chem. Phys., 1996, 104, 9047.

27 M. J. Frisch, G. W. Trucks, H. B. Schlegel, G. E. Scuseria, M. A. Robb, J. R. Cheeseman, G. Scalmani, V. Barone, G. A. Petersson and H. Nakatsuji, et al., Gaussian 09, Gaussian Inc., Wallingford, CT, 2016.

28 R. D. McCullough, S. Tristram-Nagle, S. P. Williams, R. D. Lowe and M. Jayaraman, J. Am. Chem. Soc., 1993, 115, 4910.

29 T. Erb, U. Zhokhavets, G. Gobsch, S. Raleva, B. Stühn, P. Schilinsky, C. Waldauf and C. J. Brabec, Adv. Funct. Mater., 2005, 15, 1193.

30 The use of CNT-sheet as the top electrode makes the device semi-transparent. Thus, a reflectance from the top (back) electrode was significantly reduced resulting in decrease of $J_{\mathrm{SC}}$. In addition, a slight lower conductivity of the
CNT-sheet electrode $\left(\sim 100 \Omega / \mathrm{sq}^{-1}\right)$ compared to the metal electrodes was also a possible factor of the relatively poor $\eta$. See, S. Tanaka, A. A. Zakhidov, R. Ovalle-Robles, Y. Yoshida, I. Hiromitsu, Y. Fujita and K. Yoshino, Synth. Met., 2009, 159, 2326.

31 M. Böckmann, T. Schemme, D. H. de Jong, C. Denz, A. Heuer and N. L. Doltsinis, Phys. Chem. Chem. Phys., 2015, 17, 28616.

32 R. S. Bhatta, Y. Y. Yimer, M. Tsige and D. S. Perry, Comput. Theor. Chem., 2012, 995, 36.

33 M. Moreno, M. Casalegno, G. Raos, S. V. Meille and R. Po, J. Phys. Chem. B, 2010, 114, 1591.

34 E. F. Oliveira and F. C. Lavarda, Mater. Chem. Phys., 2014, 148, 923.

35 H. Ando, S. Tanaka, K. Matsumoto and Y. Nakao, Chem. Phys. Lett., 2017, 687, 60.

36 Y. Kim, S. Cook, J. Kirkpatrick, J. Nelson, J. R. Durrant, D. D. C. Bradley, M. Giles, M. Heeney, R. Hamilton and I. McCulloch, J. Phys. Chem. C, 2007, 111, 8137.

37 M. C. Scharber, D. Mühlbacher, M. Koppe, P. Denk, C. Waldauf, A. J. Heeger and C. J. Brabec, Adv. Mater., 2006, 18, 789.

38 H. Sirringhaus, P. J. Brown, R. H. Friend, M. M. Nielsen, K. Bechgaard, B. M. W. Langeveld-Voss, A. J. H. Spiering, R. A. J. Janssen, E. W. Meijer, P. Herwig and D. M. de Leeuw, Nature, 1999, 401, 685.

39 M. Brinkmann, J. Polym. Sci., Part B: Polym. Phys., 2011, 49, 1218.

40 R. Österbacka, C. P. An, X. M. Jiang and Z. V. Vardeny, Science, 2000, 287, 839.

41 A. Zen, M. Saphiannikova, D. Neher, J. Grenzer, S. Grigorian, U. Pietsch, U. Asawapirom, S. Janietz, U. Scherf, I. Lieberwirth and G. Wegner, Macromolecules, 2006, 39, 2162.

42 N. Chandrasekaran, E. Gann, N. Jain, A. Kumar, S. Gopinathan, A. Sadhanala, R. H. Friend, A. Kumar, C. R. McNeill and D. Kabra, ACS Appl. Mater. Interfaces, 2016, 8, 20243. 